\title{
Zuma Modified Maneuver as a Treatment to Geotropic Lateral Semicircular Canal Benign Paroxysmal Positional Vertigo
}

\author{
Bernardo Faria Ramos ${ }^{1}$ Renato Cal ${ }^{2}$ Camila Martins Brock ${ }^{3}$ Pedro Luiz Mangabeira Albernaz ${ }^{4}$ \\ Francisco Zuma e Maia ${ }^{3}$
}

${ }^{1}$ Department of Otorhinolaryngology, Universidade Federal do Espírito Santo, Vitoria, ES, Brazil

2 Department of Otorhinolaryngology, Universidade Federal do Pará, Belem, PA, Brazil

${ }^{3}$ Department of Otorhinolaryngology, Pontifícia Universidade Católica, INSCER, Rio Grande do Sul, Porto Alegre, RS, Brazil

${ }^{4}$ Department of Otorhinolaryngology, Universidade Federal de São

Paulo, São Paulo, SP, Brazil

Int Arch Otorhinolaryngol 2021;25(2):e255-e257.

\begin{abstract}
Address for correspondence Prof. Dr. Pedro L. Mangabeira Albernaz, MD, PhD, Department of Otorhinolaryngology, Universidade Federal de São Paulo, Av. Albert Einstein, 627, Pavilion A1, Room 117, São Paulo, SP, 05652-000, Brazil (e-mail: plmalbernaz@gmail.com).
\end{abstract}

\author{
Abstract \\ Keywords \\ - geotropic lateral \\ canal benign \\ paroxysmal positional \\ vertigo \\ - vertigo \\ - repositioning \\ maneuver
}

Introduction Benign Paroxysmal Positional Vertigo (BPPV) is the most common vestibular disorder, resulting from detached otoliths that migrate to one of the semicircular canals - canalolithiasis - or one of the cupulas - cupulolithiasis. The present study is related to lateral canal BPPVs, which may be either geotropic or apogeotropic. The geotropic variant of lateral semicircular canal benign paroxysmal positional vertigo (LC-BPPV) is attributed to free floating particles in the posterior arm of the lateral semicircular canal.

Objectives To verify the possibility of employing the Zuma repositioning maneuver, with a brief modification, as an alternative treatment for geotropic LC-BPPV.

Methods Seven patients with geotropic LC-BPPV were enrolled and treated with the Zuma modified maneuver. Patients were reevaluated 1 hour after a single maneuver, to confirm the resolution of vertigo and positional nystagmus.

Results All seven patients achieved immediate resolution of vertigo and positional nystagmus as measured 1 hour after the application of the maneuver.

Conclusion The Zuma modified maneuver was effective for geotropic LC-BPPV after a single application. The use of the Zuma maneuver for both apogeotropic and geotropic LC-BPPV may simplify the treatment of these patients.

\section{Introduction}

Benign paroxysmal positional vertigo (BPPV) is the most common vestibular disorder, resulting from detached otoliths that migrate to one of the semicircular canals - canalolithiasis - or one of the cupulas - cupulolithiasis. The posterior semicircular canals are the most commonly affected by these disorders, but lateral canals are also frequent sites; anterior semicircular canal BPPV (LC-BPPV) is less frequent. The present study is related to LC-BPPVs (LC-BPPV), which may be either geotropic or apogeotropic. The Zuma maneuver was initially designed to treat apogeotropic LC-BPPV.

The geotropic variant of LC-BPPV is attributed to free floating particles in the posterior arm of the lateral semicircular canal. It received

March 15, 2020

accepted

April 18, 2020

published online

June 23, 2020
DOI https://doi.org/

10.1055/s-0040-1712935. ISSN 1809-9777.

\footnotetext{
(C) 2020. Fundação Otorrinolaringologia. All rights reserved.

This is an open access article published by Thieme under the terms of the Creative Commons Attribution-NonDerivative-NonCommercial-License, permitting copying and reproduction so long as the original work is given appropriate credit. Contents may not be used for commercial purposes, or adapted, remixed, transformed or built upon. (https://creativecommons.org/ licenses/by-nc-nd/4.0/) Thieme Revinter Publicações Ltda., Rua do Matoso 170, Rio de Janeiro, RJ, CEP 20270-135, Brazil
} 
is characterized by horizontal nystagmus beating to the side of the head turn in the supine roll test. On the other hand, the apogeotropic variant of LC-BPPV is attributed to free floating particles in the anterior arm of the lateral semicircular canal, particles attached to the cupula facing the canal or particles attached to the cupula facing the utricule. It is characterized by horizontal nystagmus beating to the opposite side of the head turn in the supine roll test. ${ }^{1-3}$

Different types of reposition maneuvers have been proposed for the management of geotropic and apogeotropic LCBPPV: Gufoni maneuver, Zuma maneuver, Forced Prolonged Position (Vannucchi Technique) and Barbecue Rotation (Lempert maneuver, Vannucchi-Asprella maneuver). ${ }^{4-9}$

For practical reasons, since there are several types of reposition maneuvers described for LC-BPPV, it was felt that the Zuma maneuver, with a brief modification (Zuma modified maneuver) could be an alternative treatment for geotropic LC-BPPV.

\section{Methods}

The Zuma modified maneuver proposed to geotropic LCBBPV was based on the 3D biomechanical model designed by Rajguru et $a l,{ }^{10,11}$ as the original maneuver. The present study was approved by the Ethics Committee (protocol number CAEE 06137012.3.2002.5349).

A retrospective study was conducted on seven consecutive patients who were diagnosed with geotropic LC-BPPV, all without a history of trauma or concomitant neurotological disease. - Table 1 gives information on the patients, as well as the affected sides.

Benign paroxysmal positional vertigo was diagnosed when characteristic horizontal nystagmus was demonstrated in the supine head roll test or in the McClure-Pagnini test and the Seated Supine Positioning Test (SSPT) $)^{12,13}$ using a Video Frenzel goggle (Interacoustics, Middelfart, Denmark). The McClure-Pagnini test was performed by turning the head $90^{\circ}$ to each side in the supine position. Since it is performed on the yaw plane, it should be more correct to call it the head yaw test (HYT) while supine. ${ }^{14,15}$ In the SSPT, the patient is briskly brought from the seated position to the supine position. ${ }^{12,13}$

All of the patients were treated with the Zuma modified maneuver. The modification from the original maneuver is a head turning $45^{\circ}$ to the unaffected side, in the sitting position (step I). Then, the patient is asked to lie down on the affected

Table 1 Age, Gender and Affected Side of the Patients

\begin{tabular}{|l|l|l|l|}
\hline Patient & Age in Years & Gender & Affected side \\
\hline 1 & 48 & female & left \\
\hline 2 & 59 & female & left \\
\hline 3 & 68 & male & left \\
\hline 4 & 52 & female & left \\
\hline 5 & 67 & female & right \\
\hline 6 & 58 & female & left \\
\hline 7 & 63 & male & right \\
\hline
\end{tabular}

side (step II). Next, the patient moves into dorsal decubitus and the head is turned $45^{\circ}$ toward the unaffected side (step III). After that, the head is turned $90^{\circ}$ toward the unaffected side (step IV). Finally, the patient's head is tilted slightly forward, followed by a slow return to the sitting position (step V). (-Fig. 1). There is no age limit for the use of this maneuver.

After the performance of the modified Zuma maneuver, its immediate therapeutic efficacy was determined by the same neurotologist. Patients were reevaluated 1 hour after a single maneuver, to confirm the resolution of vertigo and positional nystagmus.

\section{Results}

All seven patients achieved immediate resolution of vertigo and positional nystagmus as measured 1 hour after the application of the maneuver.

\section{Discussion}

We suggest that the Zuma maneuver with a brief modification (Zuma modified maneuver) could be an alternative treatment for the geotropic variant of LC-BPPV.

There are several types of maneuvers described to treat LC-BPPV, and some of them have to be performed toward the unaffected side of the patient (i.e., Guffoni maneuver) ${ }^{4}$ and others toward the affected side (i.e., Zuma maneuver). ${ }^{5} \mathrm{~A}$ single maneuver with a brief modification, for both geotropic and apogeotropic LC-BPPV, could simplify the treatment of these cases, following the concept that the repositioning of the otoliths should be performed from the affected side toward the healthy side.

The modification from the original maneuver consists in a $45^{\circ}$ head turning to the unaffected in the sitting position (step I). Hence, when the patient is lied down toward the affected side (step II), the lateral canal is placed in a vertical plane and the otoliths start moving away from the ampulla into the posterior arm. In the step IV, when the head is turned $90^{\circ}$ toward the unaffected side, the posterior arm of the canal is placed in the vertical plane, making the otoliths move away from the ampulla, through the posterior arm of the canal, in the direction of the utricule. The head tilting that is also performed in the original maneuver prevents the particles from moving back to the canal.

As the particles are free floating on the canal, there is no need of the brisk acceleration that is used to detach the otoliths from the cupula in cases of cupulolithiasis. There is also no need to wait for 3 minutes in each position, like in the original maneuver, for the same reason.

\section{Conclusion}

Despite the small sample of patients, the Zuma modified maneuver was effective for geotropic LC-BPPV after a single application. Further studies, however, are needed to evaluate the efficacy of this maneuver. The use of the Zuma maneuver for both apogeotropic and geotropic LC-BPPV may simplify the treatment of these patients. 


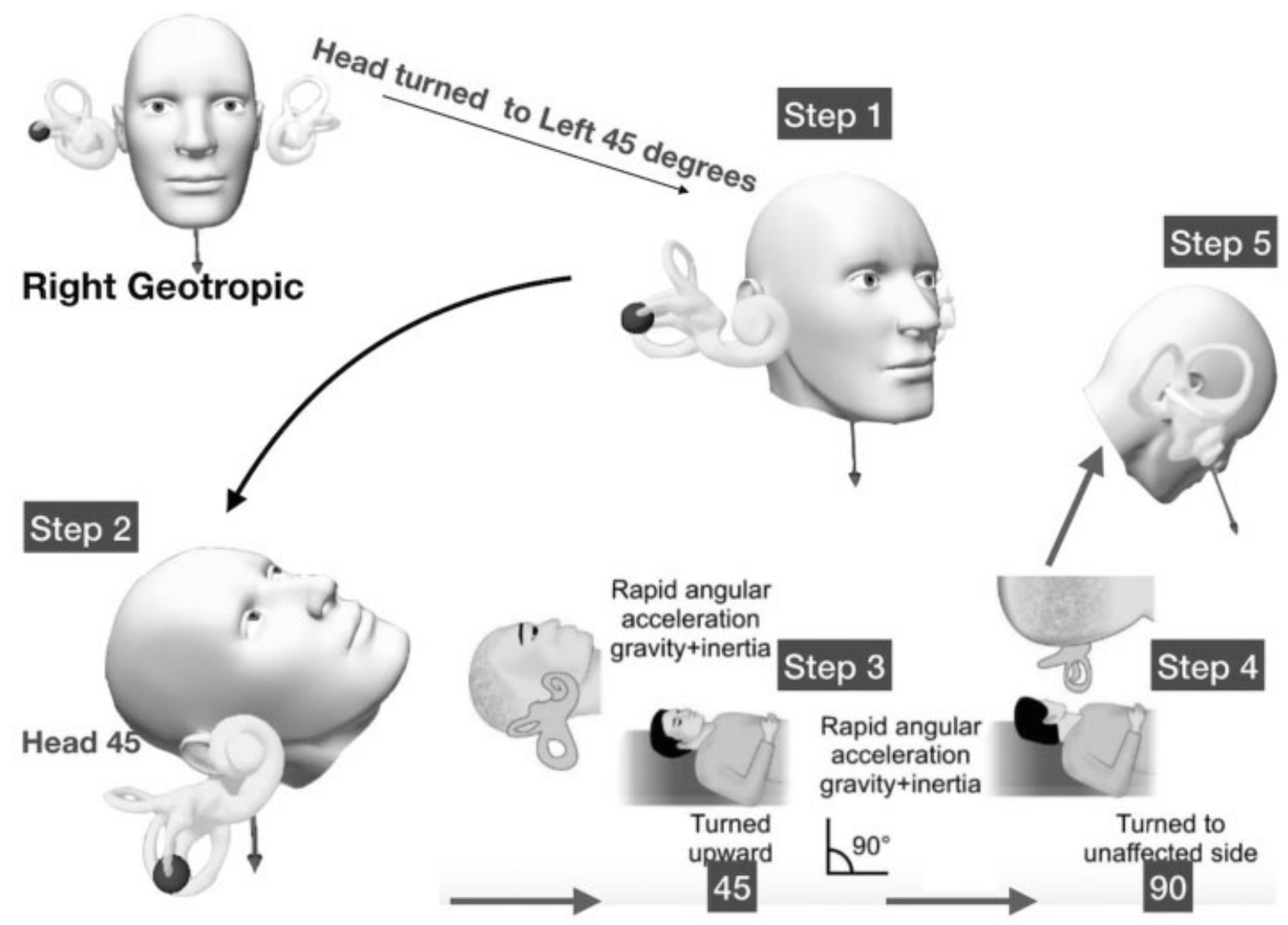

Fig. 1 The modification from the original maneuver is a head turning $45^{\circ}$ to the unaffected side in the sitting position (step I). Then the patient is asked to lie down on the affected side (step II). Next, the patient moves into dorsal decubitus and the head is turned $45^{\circ}$ toward the unaffected side (step III). After that, the head is turned $90^{\circ}$ toward the unaffected side (step IV). Finally, the patient's head is tilted slightly forward, followed by a slow return to the sitting position (step V). Data modified from Zuma e Maia 2016. ${ }^{5}$

Note

Approved by the Ethical Committee of the Universidade Luterana Brasileira (ULBRA RS, in the Portuguese acronym), Canoas, Brazil - CAEE 06137012.3.2002.5349.

Contributions

All authors contributed equally.

Conflict of Interests

The authors have no conflict of interests to declare.

\section{References}

1 Schubert MC. Stop the world - I want to get off. Vestibular SIG Newsletter. BPPV Special Ed 2013:17

2 Baloh RW, Yue Q, Jacobson KM, Honrubia V. Persistent directionchanging positional nystagmus: another variant of benign positional nystagmus? Neurology 1995;45(07):1297-1301

3 Steddin S, Ing D, Brandt T. Horizontal canal benign paroxysmal positioning vertigo (h-BPPV): transition of canalolithiasis to cupulolithiasis. Ann Neurol 1996;40(06):918-922

4 Mandalà M, Pepponi E, Santoro GP, et al. Double-blind randomized trial on the efficacy of the Gufoni maneuver for treatment of lateral canal BPPV. Laryngoscope 2013;123(07):1782-1786

5 Zuma e Maia F. New treatment strategy for apogeotropic horizontal canal benign paroxysmal positional vertigo. Audiology Res 2016;6(02):163

6 Ramos BF, Cal R, Brock CM, Albernaz PLM, Maia FZE. Apogeotropic variant of horizontal semicircular canal benign paroxysmal positional vertigo: Where are the particles? Audiology Res 2019;9(02):228

7 Asprella Libonati G, Gagliardi G, Cifarelli D, Larotonda G. "Step by step" treatment of lateral semicircular canal canalolithiasis under videonystagmoscopic examination. Acta Otorhinolaryngol Ital 2003;23(01):10-15

8 Lempert T, Tiel-Wilck K. A positional maneuver for treatment of horizontal-canal benign positional vertigo. Laryngoscope 1996; 106(04):476-478

9 Vannucchi P, Asprella-Libonati G, Gufoni M. The physical treatment of lateral semicircular canal canalolithiasis. Audiol Med 2005;3:52-56

10 Rajguru SM, Ifediba MA, Rabbitt RD. Biomechanics of horizontal canal benign paroxysmal positional vertigo. J Vestib Res 2005;15 (04):203-214

11 Rajguru SM, Ifediba MA, Rabbitt RD. Three-dimensional biomechanical model of benign paroxysmal positional vertigo. Ann Biomed Eng 2004;32(06):831-846

12 Nuti D, Vannucchi P, Pagnini P. Lateral canal BPPV: Which is the affected side? Audiol Med 2005;3:16-20

13 Asprella Libonati G. Diagnostic and treatment strategy of lateral semicircular canal canalolithiasis. Acta Otorhinolaryngol Ital 2005;25(05):277-283

14 Pagnini P, Nuti D, Vannucchi P. Benign paroxysmal vertigo of the horizontal canal. ORL J Otorhinolaryngol Relat Spec 1989;51(03): $161-170$

15 Nuti D, Vannucchi P, Pagnini P. Benign paroxysmal positional vertigo of the horizontal canal: a form of canalolithiasis with variable clinical features. J Vestib Res 1996;6(03):173-184

16 MacDougall H, Rogers S. AVOR - Angular Vestibulo-Ocular Reflex. Available from: http://www.psych.usyd.edu.au/HumanFactors/?page_id=2160 